DOI: https://doi.org/10.24127/ajpm.v8i1.1810

\title{
ANALISIS SARANG LEBAH MADU DALAM GEOMETRI MATEMATIKA DAN ALQURAN
}

\author{
Cindy Dwi Novitasari ${ }^{1}$, Bambang Sri Anggoro ${ }^{2}$, Komarudin $^{3}$ \\ ${ }^{1,2,3}$ Pendidikan Matematika, Universitas Islam Negeri Raden Intan Lampung \\ E-mail: cindydwinovitasari79@gmail.com ${ }^{1)}$ \\ bambang2802@yahoo.com ${ }^{2}$ \\ komarudin@radenintan.ac.id ${ }^{3)}$
}

Received 30 Januari 2019; Received in revised form 9 April 2019; Accepted 10 May 2019

\begin{abstract}
The purpose of this study was to obtain scientific evidence about the features of honey bee hives in two aspects, namely mathematical geometry, and the Qur'an. The research method used is qualitative research. Where research is conducted is library research by conducting content analysis with the conceptual realm. The process of data analysis is done with a preliminary study looking for references, followed by data collection, then conclusions will be drawn, then the data is validated in the form of triangulation methods. The results of the study show that hexagon is the optimal form when viewed in mathematical geometry because compared to other forms of hexagonal has the largest capacity area with a small circumference so that it requires little raw material for making nests. In addition, the hexagon is very possible in making the nest there is no gap between one cavity and the other cavity. Whereas reviewed in the Qur'an shows that the hexagon shape is very symmetrical and the selection of the nested form is inseparable from the intervention of Allah SWT, which Allah has given the miracle of being a bee in the form of revelation to create a nest with all its features.
\end{abstract}

Keywords: Honeycomb; Hexagon; Alquran.

\section{PENDAHULUAN}

Matematika ialah pelajaran yang membutuhkan penalaran dan proses pemahaman konsep yang berkesinambungan (Anggoro, 2016). Bagi para ahli matematika, keindahan sesungguhnya dari matematika terletak pada pola penalaran yang berupa interkoneksi argument-argumen logis (Suandito, 2017). Kenyataan menunjukkan, sebagian besar kehidupan manusia berhadapan dengan masalah-masalah sehingga perlu mencari penyelesaiannya (Yanti \& Syazali, 2016).

Pada dasarnya di dalam Alquran, Allah SWT berulang kali mengungkapkan tentang ilmu matematika meskipun secara tersirat, namun maknanya tetap mengarah ke yang dituju. Karena Alquran adalah satu-satunya pesan samawi yang mampu menjaga orisinilitasnya sepanjang sejarah (Mubaroh, Mujib, \& Syazali, 2016). Akomodasi terhadap konteks ilmiah dalam studi Alquran sangatlah urgen. Hal demikian dapat mengungkap nilai-nilai integrative dalam ayat Alquran itu sendiri, di samping memberi 'legalitas ilahiyah' dari temuan ilmiah kekinian.(Iskandar, 2016) Prihal inilah yang kemudian menjadikan munculnya alasan intelektual untuk menggali tentang ilmu pengetahuan.Semua ini membuktikan bahwa antara ilmu pengetahuan dengan Islam tidak dapat dipisahkan.

$$
\text { Realitas kebenarannya yang }
$$
terdapat dalam Islam di mana bersumber pada wahyuAllah SWT lebih terjamin, selain itu sifatnya juga absolut dan dapat dipercaya karena Islam 
bukanlah datang dari manusia yang kemampuannya sangat terbatas. Ayatayat Alquran yang memerintahkan manusia mencari ilmu atau menjadi ilmuwan (Fakhri, 2010). Itulah megapa Allah SWT memerintahkan kita untuk membaca.

Dari begitu banyaknya rentetan keajaiban ilmiah yang terdapat di dalam Alquran salah satunya adalah lebah, sebagaimana firman-Nya:

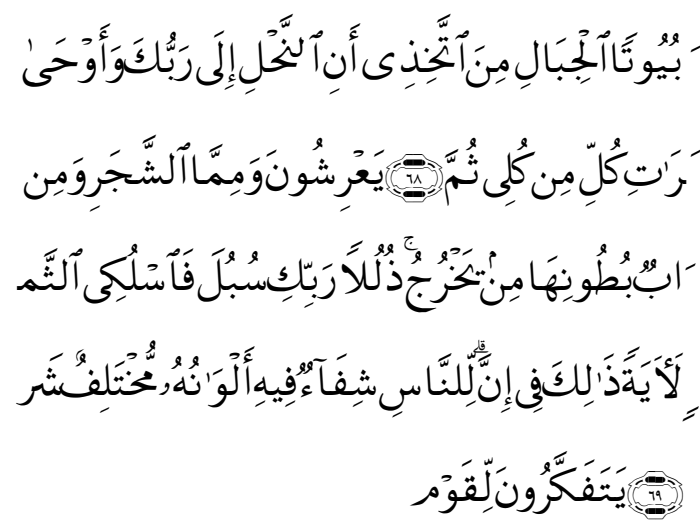

Artinya:"Dan Tuhanmu mewahyukan kepada lebah: "Buatlah sarang-sarang di bukit-bukit, di pohon-pohon kayu, dan di tempat-tempat yang dibikin manusia.Kemudian makanlah dari tiaptiap (macam) buah-buahan dan tempuhlah jalan Tuhanmu yang Telah dimudahkan (bagimu). dari perut lebah itu ke luar minuman (madu) yang bermacam-macam warnanya, di dalamnya terdapat obat yang menyembuhkan bagi manusia. Sesungguhnya pada yang demikian itu benar-benar terdapat tanda (kebesaran Tuhan) bagi orang-orang yang memikirkan." (Q.S. An-Nahl: 68-69)

Jenis lebah madu para pakar mengemukakan pendapat yang berbeda di antara para pakar lebah madu sendiri mengenai jumlah lebah madu (Hadisoesilo, 2001). Tempat tinggal dan kehidupan lebah umumnya dan lebah madu khususnya terdapat bukti nyata yang sangat agung mengenai kemampuan serta keluasan akan ilmu Allah SWT melalui kejadian ilmiah yang sangat diluar nalar yang ada dalam Alquran (Hilda, 2016). Berbagai saintis yang telah melakukan pengkajian tentang kehidupan dan tingkah laku dari lebah madu serta tempat tinggal lebah madu.

Terdapat berbagai kelebihan dan keistimewaan dari apa yang dilakukan oleh lebah, diantaranya adalah bahwa lebah membentuk kantung-kantung sel penyimpanan madu berbentuk sebuah bidang geometri segienam (Sari, 2014). Begitu menakjubkannya tentang lebah madu yang membuat rumah mereka, jika di telaah lebih dalam mengenai arsitek rumah yang lebah madu buat sungguh dapat membuat mata manusia takjub dibuatnya.Segienam yang terbentuk sangatlah simetri.Anehnya, tidak dijumpai bentuk cacat apapun pada titik sambungnya.Allah SWT menyatakan dalam Alquran bahwasannya lebah sebenarnya berperilaku berdasarkan atas ilham yang diberikan-Nya.

Sarang lebah memiliki bentuk heksagonal atau segienam sebagai tempat untuk penyimpanan madu.Bentuk heksagonal yang luar biasa simetris, jika tiap rongga digabungkan akan menghasilkan suatu kombinasi ruang yang sempurna, sehingga tidak akan menghasilkan suatu ruang sisa yang tidak berguna, seperti halnya ruang-ruang dengan penampang segitiga atau segiempat. Faktanya lebah tidak menggunakan perhitungan matematis yang rumit melainkan menggunakan fitrahnya, yang diberikan atau "diilhami" langsung oleh Allah SWT.

Salah satu penelitian tentang kajian bentuk sarang lebah yang telah dilakukan oleh Mutia Sari (2014) memberikan kesimpulan bahwa segienam beraturan merupakan satu- 
satunya bidang geometri yang unggul dalam lemma pemotongan dibandingkan dengan segi lainnya dan memiliki kapasitas luas terbesar serta keliling terkecil. Penelitian lain juga pernah dilakukan oleh Lelya Hilda (2016) memberikan kesimpulan lebah madu mampu membuat sarang berbentuk heksagonal yang sempurna, dan menunjukkan bahwa antara sains tidak lepas dari Islam. Pembahasan tersebut di atas menunjukkan bahwa sarang lebah memiliki keistimewaan tersendiri jika ditinjau dalam aspek matematika.

Hal inilah yang menjadikan dasar untuk mengkaji bentuk sarang lebah madu ditinjau dari bentuk geometrinya dan mengaitkannya dalam Alquran karena berdasarkan penelitian terdahulu belum dijelaskan secara rinci keistimewaan bentuk sarang lebah madu dalam geometri matematika dan terdapatnya keterkaitan dengan Alquran.Tujuan dalam penelitian ini adalah untuk memperoleh bukti ilmiah mengenai keistimewaan sarang lebah madu dalam dua aspek yaitu geometri matematika dan Alquran.

\section{METODE PENELITIAN}

Penelitian yang dilakukan berupa penelitian kepustakaan, yaitu serangkaian penelitian yang merupakan metode pengumpulan data kepustakaan atau penelitian yang memperoleh obyek penelitian melalui sumber informasi kepustakaan. Sehingga analisis data yang digunakan yaitu dengan analisis konten/isi (content analysis) dengan kajian kualitatif menggunakan ranah konseptual (Gunawan, 2015).

Proses analisis data dilakukan dengan studi pendahuluan mencari referensi, dilanjutkan pengumpulan data, lalu akan ditarik kesimpulan, selanjutnya melakukan keabsahan data berupa triangulasi metode. Triangulasi metode yang dilakukan yaitu dengan membandingkan informasi/data dengan pengecekan kebenaran yang berbeda. Selain menggunakan literasi, informan juga akan digunakan agar informasi yang didapat memperoleh keabsahan data.

\section{HASIL PENELITIAN DAN PEMBAHASAN}

\section{A. Sarang Lebah Madu dalam Geometri Matematika \\ Matematika merupakan pelajaran} yang menjadi satu unsur penting meningkatnya ilmu pengetahuan serta teknologi (Kusuma, 2017). Sarang lebah memiliki desain geometri yang apik, di mana merupakan salah satu implementasi pembelajaran matematika. Geometri di sini diperlukan seperti matematika dan bahasa sebagai salah satu bentuk yang dimiliki untuk berkomunikasi dengan benuk bilangan dan lambing-lambang (Mochsen Sir, 2005). Pengamatan sarang lebah madu yang telah dilakukan menguak fakta bahwa sarang lebah berbentuk segi enam, namun ada beberapa sarang yang terbentuk memiliki bentuk lingkaran.Selain lingkaran ada pula bentuk segi enam tidak beraturan.

Sarang lebah madu memiliki bentuk yang sangat unik dan menakjubkan. Fakta yang sangat mengejutkan, di mana seekor lebah dengan kemampuannya dapat membangun sarang dengan sebaik itu. Karena sangatlah mustahil jika lebah mampu membangun sarang dengan desain yang sangat canggih tanpa melalui perhitungan yang rumit. Pertanyaannya, mengapa lebah dapat membuat dan memilih bentuk heksagonal untuk bentuk dari sarangnya. 
1. Poligon Beraturan dan Pengubinan

Secara geometri, bentuk sarang lebah madu selain berbentuk segi enam juga memiliki kemungkinan berbentuk segi- $n$ beraturan yang lainnya.Namun, pada kenyataannya yang terbentuk adalah heksagonal. Hal inilah yang akan dibuktikan dengan penjelasan matematis.

Bentuk heksagonal yang simetris, jika digabungkan akan menghasilkan kombinasi ruang guna yang sempurna, yaitu tidak menghasilkan ruang-ruang sisa yang tak berguna, seperti jika ruang-ruang yang berpenampang lingkaran atau segi lima.

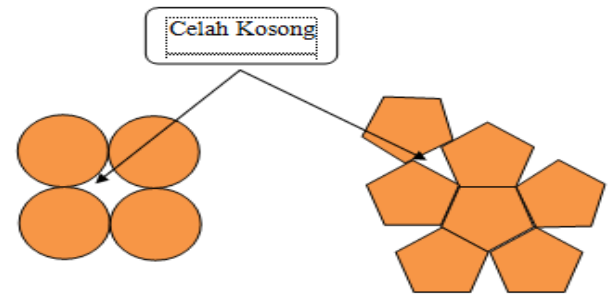

Gambar 1. Penampang lingkaran dan segi lima

Berdasarkan Gambar 1 di atas, terlihat bahwa kedua bentuk baik lingkaran ataupun segi lima memiliki celah. Sehingga kombinasi ruang guna yang terbentuk tidak sempurna.Kemudian bagaimana dengan bentuk ruang segi tiga atau segi empat. Apakah memiliki kombinasi yang lebih optimal.Perhatikan ilusi pada gambar 2.
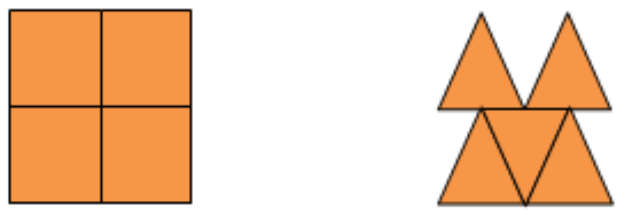

Gambar 2. Penampang segi empat dan segi tiga

Perhatikan Gambar 2, baik segi empat ataupun segi tiga memiliki ruang guna yang optimal di mana tidak terdapat celah antar ruangnya.
Poligon beraturan adalah poligon dengan semua panjang sisinya sama dan ukuran tiap sudutnya juga sama. Besar tiap sudut interior dari poligon-poligon yang saling berdekatan tanpa meninggalkan ruang kosong dengan satu titik yang bersekutu adalah sama dengan $360^{\circ}$, seperti terlihat pada gambar 3 .
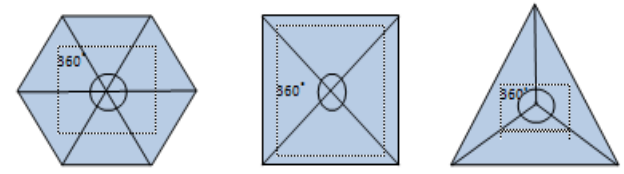

Gambar 3. Poligon beraturan yang berdampingan membentuk sudut $360^{\circ}$ dengan satu titik yang bersekutu

Banyak jenis model pengubinan dengan poligon beraturan dapat dianalisis dengan besar sudut suatu poligon beraturan yang mengubin disekeliling sebuah titik. Landasan dasarnya bahwa jumlah semua sudut poligon yang saling mengubin dengan sebuah titik yang bersekutu tanpa ruang yang tersisa adalah $360^{\circ}$, maka pengukuran sudut interior tiap sudut poligon beraturan segi- $n$ adalah (Rich \& Thomas, 2009):

$$
\frac{n-2}{n} \times 180^{\circ}
$$

Berdasarkan pengukuran tiap sudut interior suatu poligon beraturan pada persamaan di atas, jika banyaknya suatu poligon yang saling berdekatan tanpa ruang yang tersisa, maka jumlah tiap sudut interior dari sisi-sisi yang berdampingan dengan satu titik yang bersekutu adalah sama dengan $360^{\circ}$, secara sistematis dapat dinyatakan dengan,

$$
\begin{gathered}
N\left[\frac{180^{\circ}(n-2)}{n}\right]=360^{\circ} \\
N\left[180^{\circ}(n-2)\right]=360^{\circ} . n \\
N=\frac{360^{\circ} \cdot n}{180^{\circ}(n-2)}
\end{gathered}
$$


DOI: https://doi.org/10.24127/ajpm.v8i1.1810

dengan,

$$
N=\frac{2 n}{(n-2)}
$$

$N=$ banyak poligon beraturan yang dapat berdampingan membentuk sudut $360^{\circ}$

$n$ = banyak sisi

Tabel 1. Banyak poligon yang saling mengubin tanpa ruang sisa

\begin{tabular}{cc}
\hline $\boldsymbol{n}$ & $\boldsymbol{N}$ \\
\hline 3 & 6 \\
4 & 4 \\
5 & 3,333 \\
6 & 3 \\
7 & 2,8 \\
8 & 2,667 \\
9 & 2,571 \\
10 & 2,5 \\
$\ldots$ & $\ldots$ \\
$\ldots$ & $\ldots$ \\
\hline
\end{tabular}

Poligon beraturan berupa segi tiga, segi empat, segi lima dan segi enam, secara berurutan didapatkan $N$ $=6,4,3,333,3,2,8,2,667,2,571$, dan 2,5. Nilai $N$ dengan bilangan bulat hanya dihasilkan untuk $n=3$, 4, dan 6. Sedangkan tidak didapatkan nilai dengan bilangan bulat dari nilainilai setelai $n>6$ seperti yang terlihat dalam Tabel 1.Ini berarti untuk pengubinan hanya dapat dipenuhi oleh poligon beraturan yang berupa segi tiga, segi empat, dan segi enam.Kesimpulan awal poligon yang memungkinkan dalam pembuatan sarang lebah tanpa adanya celah dari tiap ruangnya adalah segi tiga, segi empat, dan segi enam.

Berdasarkan pengubinan pula, dapat dilihat bahwa segi enam beraturan yang memiliki tepat enam sisi, akan terdapat pula tepat enam buah segi enam yang saling kongruen dan bersekutu antar satu sisi terhadap segi enam pusat yang juga kongruen. Oleh karena itu, jumlah kissing number untuk segi enam adalah sama dengan enam, sehingga memenuhi jumlah maksimal dari kissing number lingkaran yang juga sama dengan enam. Maka ini merupakan bentuk yang tepat dari tinjauan bahwa lebah juga membutuhkan penampung berbentuk lingkaran ketika lebah memasukkan madu ke dalam sarangnya.

2. Luas dan Keliling Poligon Beraturan

Setelah mendapatkan kesimpulan awal, selanjutnya merupakan bukti bahwa segi enam merupakan poligon yang paling tepat dan efektif dalam pembuatan sarang lebah madu.Dengan mendapatkan perbandingan keliling terhadap luas dari lingkaran dan poligon-poligon beraturan dengan menggunakan lemma pemotongan, kita dapat mengetahui poligon beraturan yang memang paling efektif. Untuk mendapatkan formulasi yang sama, terlebih dahulu didapatkan satuan dari semua poligon beraturan dan lingkaran dengan satuan yang sama pula. Dengan demikian, perbandingan dapat dilakukan dengan asumsi bahwa radius (circumradius) untuk semua bidang adalah sama, maka keliling dan luas poligon dapat menggunakan rumus di bawah ini dengan mempartisi poligon segi- $n$ menjadi $n$ buah segi tiga yang saling kongruen.

$$
\begin{gathered}
L=n \times \frac{1}{2} \times r^{2} \times \sin \frac{360^{\circ}}{n} \\
K=n \times r \times \sqrt{2-2 \cos \frac{360^{\circ}}{n}}
\end{gathered}
$$

dengan,

$L \quad=$ luas poligon beraturan segi-n 
DOI: https://doi.org/10.24127/ajpm.v8i1.1810

$K=$ keliling poligon beraturan segi-n

$n$ = banyak sisi

$r \quad$ radius (circumradius)

dengan menggunakan menggunakan rumus perbandingan keliling dan luas lingkaran maka akan didapat beberapa perbandingan dari tiap segi- $n$ dan lingkaran.

a. Perbandingan keliling dan luas lingkaran

$$
A_{l}=\frac{K_{l}}{L_{l}}=\frac{2 \pi r}{\pi r^{2}}=\frac{2}{r}
$$

dengan,

$A_{l}=$ perbandingan keliling dan luas lingkaran

$K_{l}=$ keliling lingkaran

$L_{l}=$ luas lingkaran

b. Perbandingan keliling dan luas segi enam beraturan

$$
\begin{aligned}
& A_{6}=\frac{K_{6}}{L_{6}} \\
& A_{6}=\frac{n \times r \times \sqrt{2-2 \cos \frac{360^{\circ}}{n}}}{n \times \frac{1}{2} \times r^{2} \times \sin \frac{360^{\circ}}{n}} \\
& A_{6}=\frac{6 \times r \times \sqrt{2-2 \cos 60^{\circ}}}{6 \times \frac{1}{2} \times r^{2} \times \sin 60^{\circ}} \\
& A_{6}=\frac{6 \times r \times \sqrt{2-2 \frac{1}{2}}}{3 \times r^{2} \times \frac{1}{2} \sqrt{3}} \\
& A_{6}=\frac{6 \times r \times \sqrt{2-1}}{3 \times r^{2} \times \frac{1}{2} \sqrt{3}} \\
& A_{6}=\frac{6 \times r \times \sqrt{1}}{3 \times r^{2} \times \frac{1}{2} \sqrt{3}} \\
& A_{6}=\frac{6 \sqrt{1} r}{3 \frac{1}{2} \sqrt{3} r^{2}} \\
& A_{6}=\frac{6 r}{3 \frac{1}{2} \sqrt{3} r^{2}}
\end{aligned}
$$

$$
\begin{aligned}
& A_{6}=\frac{6}{3 \frac{1}{2} \sqrt{3} r} \\
& A_{6}=\frac{4}{\sqrt{3} r} \\
& A_{6}=\frac{2,309}{r}
\end{aligned}
$$

dengan,

$A_{6}=$ perbandingan keliling dan luas lingkaran

$K_{6}=$ keliling lingkaran

$L_{6}=$ luas lingkaran

c. Perbandingan keliling dan luas segi lima beraturan

$$
\begin{aligned}
& A_{5}=\frac{K_{5}}{L_{5}} \\
& A_{5}=\frac{n \times r \times \sqrt{2-2 \cos \frac{360^{\circ}}{n}}}{n \times \frac{1}{2} \times r^{2} \times \sin \frac{360^{\circ}}{n}} \\
& A_{5}=\frac{5 \times r \times \sqrt{2-2 \cos \frac{360^{\circ}}{5}}}{5 \times \frac{1}{2} \times r^{2} \times \sin \frac{360^{\circ}}{5}} \\
& A_{5}=\frac{5 \times r \times \sqrt{2-2 \cos 72^{\circ}}}{5 \times \frac{1}{2} \times r^{2} \times \sin 72^{\circ}} \\
& A_{5}=\frac{5 \times r \times \sqrt{2-2 \times 0,309}}{5 \frac{1}{2} \times r^{2} \times 0,951} \\
& A_{5}=\frac{5 \times r \times \sqrt{2-0,618}}{5 \frac{1}{2} \times r^{2} \times 0,951} \\
& A_{5}=\frac{5 \times r \times \sqrt{1,382}}{5 \frac{1}{2} \times r^{2} \times 0,951} \\
& A_{5}=\frac{5 \sqrt{1,382} r}{2,377 r^{2}} \\
& A_{5}=\frac{5,877 r}{2,377 r^{2}} \\
& A_{5}=\frac{2,472}{r}
\end{aligned}
$$

dengan,

$A_{5}=$ perbandingan keliling dan luas lingkaran

$K_{5}=$ keliling lingkaran

$L_{5}=$ luas lingkaran 
d. Perbandingan keliling dan luas segi empat beraturan

$$
\begin{aligned}
& A_{4}=\frac{K_{4}}{L_{4}} \\
& A_{4}=\frac{n \times r \times \sqrt{2-2 \cos \frac{360^{\circ}}{n}}}{n \times \frac{1}{2} \times r^{2} \times \sin \frac{360^{\circ}}{n}} \\
& A_{4}=\frac{4 \times r \times \sqrt{2-2 \cos \frac{360^{\circ}}{4}}}{4 \times \frac{1}{2} \times r^{2} \times \sin \frac{360^{\circ}}{4}} \\
& A_{4}=\frac{4 \times r \times \sqrt{2-2 \cos 90^{\circ}}}{4 \times \frac{1}{2} \times r^{2} \times \sin 90^{\circ}} \\
& A_{4}=\frac{4 \times r \times \sqrt{2-2.0}}{2 \times r^{2} \times 1} \\
& A_{4}=\frac{4 \times r \times \sqrt{2-0}}{2 \times r^{2}} \\
& A_{4}=\frac{4 \times r \times \sqrt{2}}{2 \times r^{2}} \\
& A_{4}=\frac{4 \sqrt{2} r}{2 r^{2}} \\
& A_{4}=\frac{5,656 r}{2 r^{2}} \\
& A_{4}=\frac{5,656}{2 r} \\
& A_{4}=\frac{2,828}{r}
\end{aligned}
$$

dengan,

$A_{4}=$ perbandingan keliling dan luas lingkaran

$K_{4}=$ keliling lingkaran

$L_{4}=$ luas lingkaran

e. Perbandingan keliling dan luas segi tiga beraturan (sama sisi)

$$
\begin{aligned}
& A_{3}=\frac{K_{3}}{L_{3}} \\
& A_{3}=\frac{n \times r \times \sqrt{2-2 \cos \frac{360^{\circ}}{n}}}{n \times \frac{1}{2} \times r^{2} \times \sin \frac{360^{\circ}}{n}}
\end{aligned}
$$

$$
\begin{aligned}
& A_{3}=\frac{3 \times r \times \sqrt{2-2 \cos \frac{360^{\circ}}{3}}}{3 \times \frac{1}{2} \times r^{2} \times \sin \frac{360^{\circ}}{3}} \\
& A_{3}=\frac{3 \times r \times \sqrt{2-2 \cdot\left(-\frac{1}{2}\right)}}{3 \frac{1}{2} \times r^{2} \times \frac{1}{2} \sqrt{3}} \\
& A_{3}=\frac{3 \times r \times \sqrt{2+1}}{3 \frac{1}{2} \times r^{2} \times \frac{1}{2} \sqrt{3}} \\
& A_{3}=\frac{3 \times r \times \sqrt{3}}{3 \frac{1}{2} \times r^{2} \times \frac{1}{2} \sqrt{3}} \\
& A_{4}=\frac{3 \sqrt{3} r}{\frac{3}{4} \sqrt{3} r^{2}} \\
& A_{4}=\frac{4 r}{r^{2}} \\
& A_{4}=\frac{4}{r}
\end{aligned}
$$

dengan,

$A_{3}=$ perbandingan keliling dan luas lingkaran

$K_{3}=$ keliling lingkaran

$L_{3}=$ luas lingkaran

Tabel 2. Perbandingan Keliling dan Luas Lingkaran dan segi- $n$

\begin{tabular}{lc}
\hline $\begin{array}{c}\text { Bangun } \\
\text { Datar }\end{array}$ & $\begin{array}{c}\text { Perbandingan } \\
\text { Keliling dan } \\
\text { Luas }\end{array}$ \\
\hline Lingkaran & $\frac{\frac{2}{r}}{2,309}$ \\
Segi Enam & $\frac{2,472}{r}$ \\
Segi Lima & $\frac{2,828}{r}$ \\
Segi Empat & $\frac{4}{r}$ \\
Segi Tiga & \\
\hline
\end{tabular}

Hasil

dari penerapan perbandingan keliling terhadap luas dari lingkaran dan poligon-poligon beraturan menghasilkan persamaan 
yang mengakibatkan pertidaksamaan sebagai berikut:

$$
\begin{gathered}
\underset{r}{r}<\frac{2,309}{r}<\frac{2,472}{r}<\frac{2,828}{r}<\frac{4}{r} \\
\text { maka, } \\
A_{l}<A_{6}<A_{5}<A_{4}<A_{3}
\end{gathered}
$$

Pertidaksamaan tersebut terlihat bahwa bila suatu poligon yang memiliki lebih banyak sisi atau makin mendekati lingkaran, maka rasio perbandingan keliling dan luas yang dimiliki adalah makin kecil.Untuk memutuskan pilihan dari bidang-bidang tersebut sebagai bidang terbaik dalam struktur sarang lebah dan memenuhi Lemma Pemotongan. Dengan demikian, poligon dengan jumlah sisi yang makin mendekati lingkaran, memiliki luas yang lebih besar dan keliling yang lebih kecil.Meskipun lingkaran memiliki rasio keliling terhadap luas yang paling unggul, namun lingkaran tidak seperti segi enam beraturan yang dapat saling mengubin tanpa ada ruang sisa yang sia-sia.

Berdasarkan argumen matematika dari hasil perbandingan untuk perbandingan keliling terhadap luas bidang segi enam, segi empat, dan segi tiga yaitu:

$$
\frac{2,309}{r}<\frac{2,828}{r}<\frac{4}{r}
$$

diperoleh,

$$
A_{6}<A_{4}<A_{3}
$$

Hal tersebut menunjukkan bahwa rasio keliling terhadap luas untuk segi enam lebih kecil dari pada segi tiga dan segi empat, maka bidang geometri dari tiga pilihan tersebut yang memiliki luas kapasitas yang paling besar dengan material yang paling sedikit adalah segi enam beraturan yang memenuhi Lemma Pemotongan.
Lebah juga menghitung besar sudut antara rongga satu dengan yang lainnya pada saat membangun rumah.Suatu rongga dengan rongga dibelakangnya selalu dibangun dengan kemiringan $13^{0}$ dari bidang datar. Dengan begitu kemiringan sarang akan condong ke atas dan alhasil madu tidak akan tumpah. Sehingga dapat ditarik kesimpulan bahwa bentuk segi enam adalah bentuk teroptimal menurut geometri matematika.Hal inilah yang menjadikan bahwa bentuk segi enam merupakan bentuk yang paling istimewa dibanding dengan bentuk geometri lainnya.

\section{B. Sarang Lebah Madu dalam Alquran}

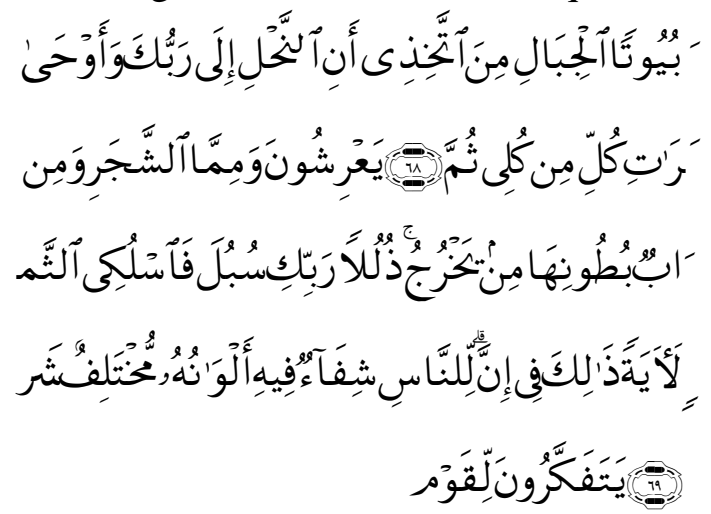

Artinya: "Dan Tuhanmu mewahyukan kepada lebah: "Buatlah sarang-sarang di bukit-bukit, di pohon-pohon kayu, dan di tempat-tempat yang dibikin manusia". Kemudian makanlah dari tiap-tiap (macam) buah-buahan dan tempuhlah jalan Tuhanmu yang Telah dimudahkan (bagimu).dari perut lebah itu ke luar minuman (madu) yang bermacam-macam warnanya, di dalamnya terdapat obat yang menyembuhkan bagi manusia. Sesungguhnya pada yang demikian itu benar-benar terdapat tanda (kebesaran Tuhan) bagi orang-orang yang memikirkan." 
1. Tafsir Q.S An-Nahl menurut Tafsir Ibnu Katsir

Pada ayat 68, hal yang digaris bawahi dan menjadi kata kuncinya adalah "dan Tuhanmu mewahyukan kepada lebah...".Ibnu Katsir memaknai kata "wahyu" sebagai petunjuk atau ilham yang diberikan Allah kepada lebah sehingga membimbing lebah agar mampu membangun sarang sebagai tempat berlindung bagi lebah yang letaknya di pegunungan, di berbagai pohon, ataupun tempat penangkaran buatan manusia.Bentuk sarang lebah yakni segi enam dengan bentuk yang kuat serta dengan segala kesempurnaannya (bagi ukuran lebah) yang membuat sarang begitu rapat menggunakan perhitungannya sehingga tidak terdapat celah lubang yang terjadi.

Ibnu Katsir juga menafsirkan ayat 69 bahwa lebah diberi oleh Allah kemampuan agar lebah memakan berbagai macam buah-buahan. Selain itu Allah memudahkan bagi lebah untuk menempuh perjalanan sejauh dan sesuai dengan kemauan lebah sendiri. Hal ini dilakukan lebah baik di darat, lembah, udara, ataupun di pegunungan, setelah melakukan perjalan dalam mecari makan, para lebah akan kembali menuju sarang mereka dengan membawa madu di mulut mereka, dan bagi lebah ratu akan melahirkan telur dan akan menjadi anakan lebah.

Selanjutnya Ibnu Katsir menafsirkan pada kalimat di ayat 69 : "Dari perut lebah itu keluar minuman yang bermacam-macam warnanya. Di dalamnya terdapat obat yang menyembuhkan bagi manusia." Madu memiliki berbagai warna yakni kuning, putih, merah, ataupun warna lainnya hal ini terjadi sesuai dengan apa warna makanan yang dimakan lebah.

Kalimat selanjutnya "ia mengandung obat bagi manusia" Ibnu Katsir memaknai kalimat ini bahwasannya pada madu terdapat banyak manfaat bagi tubuh manusia salah satunya sebagai obat. Ayat ini juga di perkuat dengan salah satu hadits shahih yang diriwayatkan oleh Qatadah dari Abu Saa'id al-Khudri r.a., (515).

Artinya: "Seseorang menemui Rasulullah saw. dan berkata, 'Yaa Rasulullah, saudaraku sakit perut (diare).' Beliau bersabdah, 'berilah dia madu.'Orang itu pulang dan memberinya madu. Tidak lama berselang, dia menemui Rasulullah kembali dan berkata, 'Ya Rasulullah, aku telah memberinya madu, tetapi diarenya berta,bah.' Beliau bersabda, 'Pulanglah dan berilah dia madu.'Orang itu pulang dan memberinya madu.Tidak lama berselang, dia menemui Rasulullah kembali dan berkata, 'Ya Rasulullah, aku telah memberinya madu, tetapi diarenya malah bertambah.' Rasulullah saw. bersabda, 'Allah benar dan perut saudaramu dusta. Pulanglah, lalu berilah dia madu. 'Dia kembali dan memberinya madu.Ternyata orang yang diare itu sembuh.'(HR Bukhari dan Muslim).

Seorang ulama ahli kedoketeran mengomentari hadits di atas: tampatnya dalam tubuh si sakit terdapat banyak endapan ampas. Tatkala dia diberi madu, sedang madu itu panas, maka endapan itu mencair dan ingin cepat keluar.Hal inilah yang membuat perutnya bertambah sakit. Orang Badui beranggapan bahwa madu telah membahayakannya, padahal madu justru akan menyembuhkannya. Setelah dia memberinya madu 
kembali, maka endapan semakin mencair dan ingin keluar.Saat diberi madu, seperti itulah yang terjadi. Namun, setelah endapan ampas yang membahayakan badan itu keluar, maka redalah perutnya, komposisinya seimbang, dan lenyaplah penyakit dan kepdihannya berkat petunjuk Nabi saw. dari Rabbnya.

Kalimat terakhir pada ayat 69 "Sesungguhnya pada demikian itu benar-benar terdapat tanda bagi orang-orang yang memikirannya" Ibnu Katsir kembali memaknai ayat tersebut bahwa pada segala bentuk pemberian yang diberikan Allah kepada lebah sebagai makhluk kecil bertubuh lemah, yang menjadikan lebah sendiri mampu terbang ke berbagai jenis tempat, dan makan bermacam-macam buah yang kemudian akan dikumpulkan untuk lilin malam dan akan menghasilkan madu dengan berbagai kashiatnya bagi tubuh manusia. Karena segala yang diberikan merupakan bentuk kekuasaan Allah yang hanya ditunjukkan bagi orang-orang yang mau untuk memikirkan segala keagunganAllah sebagai Penguasa, Pencipta serta penaklu segala. Hal inilah yang membuktikan Dia Pelaku Yang Mahakuasa, Yang Maha Bijaksana lagi Maha Mengetahui, dan Yang Maha Pemurah lagi Maha Pengasih.(Al-Mubarakfuri, 2018)

2. Tafsir Q.S An-Nahl menurut Tafsir Al-Maraghi

Kitab Al-Maraghi menafsirkan ayat 68-69 yaitu "Tuhanmu mengilhamkan dan membisikan kepada lebah serta mengajarinya berbagai pekerjaan yang membuatnya diduga makhluk berakal". Lagi-lagi kata yang harus digaris bawahi di sini adalah
mengilhamkan.Mengilhamkan

berarti memberikan petunjuk dan pengajaran bagi lebah itu sendiri.(AlMaraghi, 1993)

Kesimpulannya dari tafsir ini adalah sama dengan penafsiran dari Ibnu Katsir, yaitu semua karena "ilham" yang Allah Subhanahu wa Ta'ala berikan kepada lebah. Dengan bentuk sarang yang luar biasa istimewanya yang mampu lebah madu bangun tidaklah perlu menggunakan perhitungan matematika yang rumit atau dengan menggunakan pengukuran atau membutuhkan arsitek untuk membangunnya.Melainkan dengan petunjuk yang diberikan Allah lah sehingga lebah mampu membuat sarang lebah dengan bentuk segi enam yang simetri.

Kesimpulan dari beberapa penafsiran dan rujukan buku yang peneliti gunakan adalah sarang lebah madu memiliki bentuk yang sangat menakjubkan karena bentuk kekuasaan dari sang Pencipta. Allah Subhanahu wa Ta'ala lah yang sudah memberikan keajaiban bagi lebah dengan langsung mewahyukan kepada lebah madu untuk membuat sarang dengan segala keistimewaannya. Di tambah lagi dengan begitu banyaknya manfaat yang Allah Subhanahu wa Ta'ala berikan di dalam kandungan madu salah satunya sebagai obat sakit perut (diare) hal ini di tulis oleh Ibnu Katsir dalam tafsirnya.

Bentuk اوحى memiliki makna "wahyu" yang berbeda-beda di dalam Alquran. Sebagaimana firman Allah dalam Q.S Al- Mu'min ayat 15:

Artinya: "(Dialah) yang Maha Tinggi derajat-Nya, yang mempunyai 'Arsy, yang menurunkan wahyu dengan perintah-Nya kepada siapa yang dikehendaki-Nya di antara hambahamba-Nya, supaya dia 
memperingatkan (manusia) tentang hari pertemuan (hari kiamat)."

Pada intinya, Allah tidak hanya memberikan wahyu kepada Rasulullah saja. Melainkan Allah akan menurunkan wahyu-Nya kepada setiap hamba yang Dia kehendaki.

Bukti konkrit salah satunya ialah Allah yang mewahyukan Ibu Nabi Musa As. untuk memberikan susu (menyusui) Nabi Musa As. Di mana firman Allah dalam Q.S Al Qashash ayat 7 :

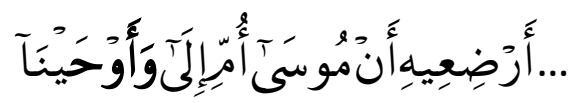

Artinya :

"Dan

kami

ilhamkan kepada ibu Musa; "Susuilah dia ..."

Selain wahyu kepada ibu Nabi Musa As. ada pula wahyu kepada bumi. Dalam Q.S Al-Zalzalah ayat 4-5 :

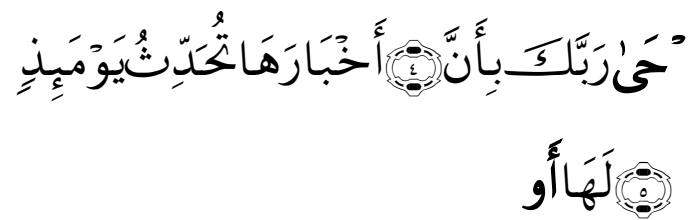

Artinya : "Pada hari itu bumi menceritakan beritanya, Karena Sesungguhnya Tuhanmu Telah mewahyukan kepadanya."

Terdapat pula jenis wahyu yang tergolong berbeda di mana pemberi wahyu tersebut bukanlah Allah. Yaitu terdapat pada firman Al-An'am ayat 112:
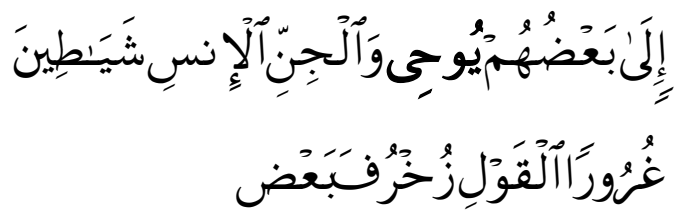

Artinya : "Yaitu syaitan-syaitan (dari jenis) manusia dan (dan jenis) jin, sebahagian mereka membisikkan kepada sebahagian yang lain perkataan-perkataan yang indah-indah untuk menipu (manusia)."
Di atas adalah beberapa bentuk pemaknaan وحى di dalam Alquran. Pemaknaan kata "wahyu" sendiri bukanlah hanya sebatas wahyu Allah kepada Nabi Muhammad SAW saja.Tetapi sejatinya wahyu memiliki konteks yang amat luas.

An-nahl ayat 68 ini merupakan salah satu buktinya, di mana ilham yang diberikan oleh Allah merupakan wahyu kepada lebah, yang secara langsung Allah berikan kepada lebah tanpa adanya perantara dalam penyampaiannya.

"Nahl"dalam An-Nahl ayat 68-69 ini merupakan derajat bagi lebah madu.Inilah alasan peneliti menggunakan ayat ini dalam penelitian ini.Karena di dalam ayat inilah menjelaskan mengenai lebah madu bukan jenis lebah lainnya yang tidak menghasilkan madu. Bukti konkritnya terletak pada ayat 69 yang mengatakan : "Dari perut lebah itu keluar minuman (madu) yang bermacam-macam warnanya..." inilah yang menjadikan para tafsir terdahulu sepakat bahwa lebah yang dimaksudkan di dalam ayat ini merupakan lebah madu.

"Kemudian makanlah dari segala (macam) buah-buahan..." Apakah benar lebah memakan buah, bukankah lebah memakan sari bunga.Kesimpulannya apakah benar yang dituliskan di dalam Alquran atau yang dikatakan guru Biologi. Hal inilah yang akan muncul apabila kita tidaklah memahami makna Satra dan Bahasa Arab yang terdapat di dalam Alquran. Bukan lagi kebimbangan yang didapat melainkan kekaguman dan kemenakjubkannya susunan bahasa Alquran itu sendiri.

Segi sastra dalam Bahasa Arab, lafadz pada ayat tersebut merupakan Majaz Mursal, di mana perkataan yang digunakan bukan bermakna yang 
sebenarnya.Karena terdapat hubungan diantara lafadz tersebut dengan makna sesungguhnya yang dikehendaki, hubungan tersebut bukanlah sebuah perumpamaan. Secara lafadznya, akal sehat akan mengatakan mustahil bagi lebah untuk memakan buah. Lebah tidak memakan buah, tetapi lebah memakan saripati bunga yag akan menjadi buah. Lebahlah yang membantu bunga dalam melakukan proses penyerbukan sehingga bunga akan menjadi buah. Inilah yang menyebabkan pembuahan.Maka hubungan pada lafadz ini adalah hubungan berupa sebab-akibat. Sehingga dapat difahami mengenai makna lafadz ayat ini ialah lebah memakan saripati bunga yang mengakibatkan penyerbukan sehingga akan terjadilah pembuahan.

Keistimewaan lebah madu itu sendiri ialah lebah memiliki keistimewaan yang diberikan oleh Allah secara langsung berupa ilham.Lebah menghasilkan manfaat dengan lebah taat kepada Allah.Allah ingin membuktikan bahwa semua alam semesta ini atas desain, mentarbiyah, dan yang mengurus adalah Allah SWT.

\section{KESIMPULAN DAN SARAN}

Sarang lebah madu memiliki keistimewaan jika ditinjau dalam persepektif geometri matematika di mana bentuk sarang lebah yang bebentuk segienam beraturan merupakan bentuk geometri (poligon beraturan) yang paling baik digunakan dibandingkan bentuk lainnya, karena dari beberapa bentuk poligon beraturan seperti segitiga, segiempat dan segilima, segienam memungkinkan dalam pembuatan sarangnya tidak terdapat celah antara satu rongga kamar ke rongga kamar lainnya (mengubin dengan baik). Selain itu jika dilihat dari luas kapasitas serta bahan baku yang digunakan, segienam memiliki luas yang paling besar, dan keliling yang kecil, sehingga menjadikan segienam berdaya tampung dengan kapasitas yang besar serta penggunaan bahan baku material yang sedikit dalam pembuatan sarang lebahnya. Inilah yang menjadikan bentuk segienam merupakan bentuk teristimewa yang dimiliki lebah madu.

Berdasarkan beberapa penafsiran dan rujukan buku yang peneliti gunakan adalah sarang lebah madu memiliki bentuk yang sangat menakjubkan karena bentuk kekuasaan dari sang Pencipta. Allah Subhanahu wa Ta'ala lah yang sudah memberikan keajaiban bagi lebah dengan langsung mewahyukan kepada lebah madu untuk membuat sarang dengan segala keistimewaannya. Jadi, bentuk segienam yang dipilih oleh lebah madu dalam membangun sarangnya merupakan bentuk campur tangan Allah Subhanahu wa Ta'ala dengan membimbing lebah madu agar membangun sarang dengan bentuk yang kuat serta rapat antara satu rongga kamar dengan rongga kamar lainnya. Di tambah lagi dengan begitu banyaknya manfaat yang Allah Subhanahu wa Ta'ala berikan di dalam kandungan madu salah satunya sebagai obat sakit perut (diare).

Sebagai seorang muslim, hendaknya kita terus membaca, mengkaji ilmu pengetahuan yang sejatinya semua ilmu pengetahuan sudah ada baik tersurat maupun tersirat di dalam Alquran sehingga menunjukkan kekuatan Alquran.Penelitian ini diharapkan dapat menambah wawasan pengetahuan serta menambahkan keimanan kita kepada Allah Subhanahu wa Ta'ala. 


\section{DAFTAR PUSTAKA}

Al-Maraghi, A. M. (1993). Tafsir AlMaraghi Jilid 14. Semarang: Toha Putra.

Al-Mubarakfuri, S. S. (2018). Shahih Tafsir Ibnu Katsir. Jakarta: Pustaka Ibnu Katsir.

Anggoro, B. S. (2016). Analisis Persepsi Siswa Smp Terhadap Pembelajaran Matematika Ditinjau Dari Perbedaan Gender Dan Disposisi Berpikir Kreatif Matematis. Al-Jabar: Jurnal Pendidikan Matematika, 7(2), 153-166.

Fakhri, J. (2010). Sains dan Teknologi dalam Alquran dan Implikasinya dalam Pembelajaran. Ta'dib: Jurnal Pendidikan Islam, 15(1), 122-142.

Gunawan, I. (2015). Metode Penelitian Kualitatif Teori dan Praktik. Jakarta: T Bumi Aksara.

Hadisoesilo, S. (2001). Keanekaragaman Spesies Lebah Madu Asli Indonesia. Biodiversitas, 2(1), 123-128.

Hilda, L. (2016). Rahasia Heksagonal pada Sarang Lebah Madu (Pandangan Sains dan Islam). Darul Ilmi, 4(1).

Iskandar, S. (2016). Studi Alquran dan Integrasi Keilmuan: Studi Kasus UIN Sunan Gunung Djati Bandung. Jurnal Ilmiah Agama dan Sosial Budaya, 1, 86-93.

Kusuma, A. P. (2017). Implementasi Model Pembelajaran Student Teams Achievement Division dan Team Assisted Individualization ditinjau dari Kemampuan Spasial Siswa. AlJabar: Jurnal Pendidikan Matematika, 8(2), 135-144.

Mochsen Sir, M. (2005). Tipologi Geometri: Telaah Beberapa Karya Frank L. Wright dan
Frank O. Gehry (Bangunan Rumah Tinggal sebagai Obyek Telaah). RONA Jurnal Arsitektur, 2(1), 69-83.

Mubaroh, U. A., Mujib, M., \& Syazali, M. (2016). Mengungkap Konsep Bilangan Prima dalam Surat AlKautsar. Al-Jabar: Jurnal Pendidikan Matematika, 7(2), 249-256.

Rich, B., \& Thomas, C. (2009). Schaum's Outlines Geometry (4 ed.). New York: Mc Graw Hill.

Sari, M. (2014). Kajian Matematika Segienam Lebah. Electronic theses and dissertations.

Suandito, B. (2017). Bukti Informal Dalam Pembelajaran Matematika. Al-Jabar: Jurnal Pendidikan Matematika, 8(1), 13-24.

Yanti, A. P., \& Syazali, M. (2016). Analisis Proses Berpikir Siswa dalam Memecahkan Masalah Matematika Berdasarkan Langkah-Langkah Bransford dan Stein Ditinjau dari Adversity Quotient. Al-Jabar: Jurnal Pendidikan Matematika, 7(1), 63-74. 